\title{
Recording of overweight and obesity as a health problem by primary care pediatricians in an electronic medical record
}

\author{
Carolina Silva, M.D. ${ }^{a}$, ValeriaMulli, M.D. ${ }^{a}$, Marcela Caffulli,M.D. ${ }^{a}$ and Julio Busaniche, M.D. ${ }^{a}$
}

\begin{abstract}
Introduction. Under-diagnosis and underrecording of overweight and obesity in pediatrics is very common. Using an electronic medical record may be helpful. The objective was to establish the percentage of recording of this problem by primary care pediatricians and analyze if it was associated with the performance of ancillary tests.

Methods. Cross-sectional study. The recording of this problem among overweight and obese pediatric patients and the presence of blood glucose, triglycerides, and high-density lipoprotein cholesterol results in obese patients were assessed.

Results. A total of 7471 overweight and obese patients were included; this health problem was adequately recorded in only $19 \%$. Among all obese patients $(n=1957), 44 \%$ had adequate recording of this health problem; $32 \%$ had lab test results showing a significant association among outcome measures.

Conclusions. The percentage of overweight and obesity recording and ancillary test performance was low. Recording was associated with a higher level of test ordering.

Key words: overweight, obesity, documentation, electronic medical record.
\end{abstract}

http:/ / dx.doi.org/10.5546/ aap.2020.eng.132

To cite: Silva C, Mulli V, Caffulli M, Busaniche J. Recording of overweight and obesity as a health problem by primary care pediatricians in an electronic medical record. Arch Argent Pediatr 2020;118(2):132-135.

a. Hospital Italiano de Buenos Aires and Instituto Universitario del Hospital Italiano de Buenos Aires, Autonomous City of Buenos Aires.

E-mail address:

Carolina Silva, M.D.:

carolina.silvablanco@gmail.com

Funding: None.

Conflict of interest: None.

Received: 1-16-2019

Accepted: 9-9-2019

\section{INTRODUCTION}

Overweight and obesity are a worldwide epidemic affecting approximately a third of children and adolescents. ${ }^{1}$ Body mass index (BMI) is useful for diagnosis in clinical practice and should be estimated, together with the BMI percentile, annually in every child as of 2 years old. A child is defined as overweight if his/her BMI is between P85 and P97 for his/ her age and sex, and obese if his/ her BMI is greater than P97. ${ }^{2}$ Excess weight implies an increased risk, in the present and future, for different conditions, especially metabolic syndrome. There is consensus about the need to screen obese children for dyslipemia and diabetes through blood glucose, total cholesterol, highdensity lipoprotein (HDL) cholesterol, low-density lipoprotein (LDL) cholesterol, and triglycerides. ${ }^{3}$

Overweight and obesity diagnosis depends on primary care physicians. However, many of these children and adolescents are not identified by their pediatricians. ${ }^{4,5}$ The recording of obesity as a health problem is also suboptimal. ${ }^{6,7}$ In addition, even those who are diagnosed do not always receive counseling or comply with ancillary tests. ${ }^{8,9}$ Recording anthropometric data in an electronic medical record (EMR) may help with the identification and proper followup of patients with overweight and obesity. ${ }^{10}$

There is no information about the extent to which overweight and obesity are currently recorded as a problem in our population. The objective of this study was to establish the percentage of overweight and obesity recording as a health problem in the pediatric population of Hospital 
Italiano de Buenos Aires (HIBA). The secondary objective included the analysis of whether the recording of this problem was associated with the recommended lab tests in obese children.

\section{MATERIALS AND METHODS}

Cross-sectional study conducted between July 2016 and June 2017. The following inclusion criteria were defined: male and female patients aged 2 to 19 years seen during a scheduled appointment and diagnosed with overweight or obesity based on their BMI, according to their weight and height as recorded in their EMR in the past 12 months. Data from unscheduled visits and primary care physicians who were not part of the Department of Clinical Pediatrics (family physicians or other specialists) were excluded. The BMI corresponded to that measured in the most recent visit included in the study period, and the World Health Organization standards were used to define overweight and obesity. ${ }^{11}$

\section{Recording of overweight and obesity as a problem}

An automatic search of the terms "overweight" and "obesity" was done in the active health problems recorded in the EMR. Adequate recording was defined as the presence of any of these terms based on the proper recognition of excess weight as a health problem. The percentage of recording was estimated overall and for each primary care physician individually.

\section{Ancillary tests}

The percentage of lab tests recommended for the screening of associated complications was estimated in the sub-population of patients who were obese (BMI greater than P97) and members of the Hospital Italiano health plan (HIHP). To this end, the presence of results for blood glucose, HDL cholesterol, and triglycerides in the EMR in the 12 months before and after overweight and / or obesity diagnosis was identified.

Only obese patients were included because there was no consensus on which tests should be ordered in overweight patients. Obese children who had a health coverage other than HIHP were not included in the analysis to reduce the possibility of lab tests done outside the hospital's setting. Besides, only the presence of the three lab values at the same time were considered because, otherwise, the study might have other screening reasons than obesity-associated complications.

To assess the association between obesity recording as a problem and the performance of lab tests to screen for complications, a bivariate analysis was done, and the $\chi^{2}$ test and $p$-value were estimated. The Stata software, version 13, was used.

\section{RESULTS}

A total of 7471 patients with a BMI greater than P85 for their age and sex and seen by 76 primary care pediatricians were included. Out of all patients, $19 \%$ of cases had been recorded as overweight/obesity and considered a health problem (Figure 1).

The analysis of data corresponding to each primary care physician showed that the median value for an adequate recording was $14 \%$ (interquartile range: $9-25 \%$ ). Out of 76 pediatricians, 23 had recorded overweight and obesity as a health problem in $0-10 \%$ of their patients; 27 , in $10-20 \%$; 11 , in $20-30 \%$; , in $30-$ $40 \%$; and 6 , in $40-70 \%$. The rate of recording was $20 \%$ or lower in $7 / 10$ pediatricians, and only $5 \%$ had recorded overweight or obesity in at least half of their patients.

In relation to studied obese patients $(\mathrm{n}=1957)$, the percentage of recording was $44 \%$; the three recommended lab test results were available in $32 \%$ (Figure 1). More patients had blood glucose results available, compared to triglycerides and HDL cholesterol $40 \%, 35 \%$, and $34 \%$,respectively). A statistically significant association was observed between recording the problem in the EMR and the presence of lab test results in the EMR $(p<0.01)$.

\section{DISCUSSION}

The results of this study show that, in our population, many opportunities to record overweight and obesity as a health problem are missed during the pediatric office visit. Similarly to what has been reported in the international bibliography, ${ }^{6-9}$ a very small percentage of assessed physicians had recorded overweight or obesity in at least half of their patients, when recording is expected to be close to $100 \%$. This may be partly because these health conditions are under-diagnosed: although children's weight and height are measured during medical visits, and their BMI is estimated automatically in the EMR, most likely, pediatricians fail to determine the BMI percentile in all patients. The latter may be due to a lack of time during office visits, poor training, and difficulties in how this pathology is approached..$^{12}$ In addition, a correct identification 
of this health problem by the pediatrician does not always translate into an adequate recording in the EMR.

In a study conducted at HIBA in 2007-2008 ( $\mathrm{n}=14743), 22 \%$ of children were overweight and $10 \%$ were obese, and only $11 \%$ of these cases had been adequately recorded in the EMR. ${ }^{13}$ The higher percentage of recording observed in this study may be explained by the improvements in the EMR system in the past decade and the growing knowledge about obesity and its consequences.

It is worth noting that the percentage of recording of this health problem among obese patients was higher compared to overweight ones. It has been described that overweight children have a higher risk of not being identified, ${ }^{14}$ thus missing the possibility for an early intervention in this group. The assessment of the correlation between recording overweight/obesity as a problem and the presence of lab test results in obese patients showed a significant association. This reinforces the importance of promoting an adequate diagnosis and recording to improve compliance with screening recommendations in this group.

One of the strengths of this study was the high number of patients and its conduct at a site where EMR has been broadly implemented. A weakness of this study was the inability to tell the difference between the under-recording and under-diagnosis of this pathology. In addition, given that terms were not searched in the body of free text, the proportion of patients adequately diagnosed by their pediatrician may be higher. Lastly, the lack of lab test results may not be because the pediatrician did not order them but due to low adherence by the family.

The causes of under-recording and potential improvement strategies should be further studied. EMR reminders, introducing a BMI percentile chart in the EMR, and information targeted at parents may improve the identification and follow-up of children with overweight and obesity. ${ }^{10,15}$

\section{CONCLUSION}

The rate of overweight and obesity recording as a health problem by primary care pediatricians in our population was low $(19 \%)$, as well as the performance of ancillary tests in obese children (32\%), in spite of using an EMR system. An adequate recording of this problem was associated with a higher rates of screening for complications.

\section{REFERENCES}

1. Organización Mundial de la Salud. Informe de la Comisión para acabar con la obesidad infantil 2016. [Accessed on: November $\left.14^{\text {th }}, 2018\right]$. Available at: http:/ / apps.who.int/ gb/ebwha/pdf_files/WHA69/A69_8-sp.pdf.

2. Comité Nacional de Nutrición. Obesidad: guías para su abordaje clínico. Buenos Aires, 2016. [Accessed on: November $\left.14^{\text {th }}, 2018\right]$. Available at: https://www.sap. org.ar/uploads/ consensos / obesity-gu-iacuteas-para-suabordaje-cl-iacutenico-2015.pdf.

3. Comité Nacional de Nutrición. Guías de práctica clínica para la prevención, el diagnóstico y el tratamiento de la obesidad. Arch Argent Pediatr. 2011; 109(3):256-66.

FIGURE 1. Overweight/obesity recorded as a health problem and performance of ancillary tests in obese children. Flow chart of studied patients

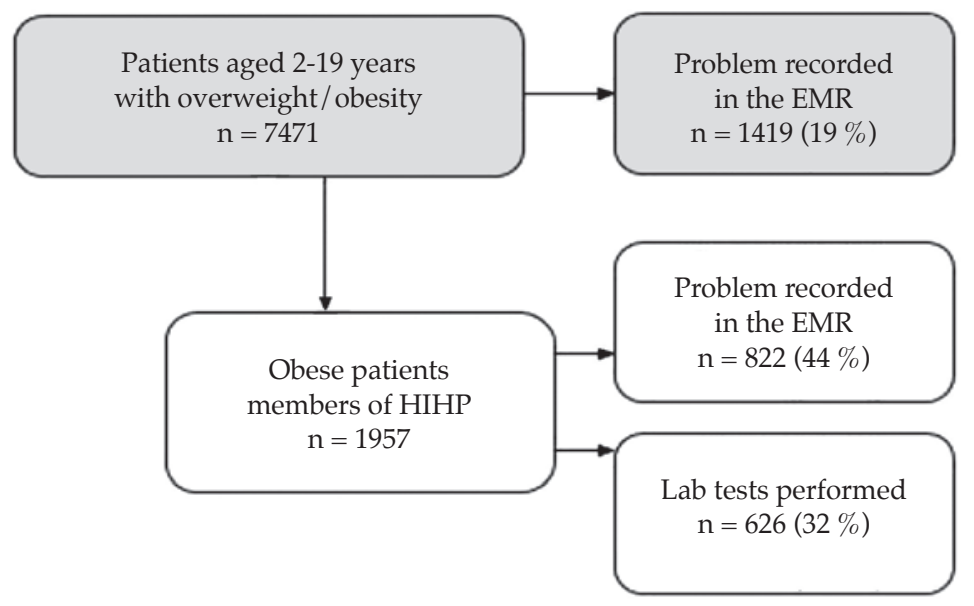

EMR: electronic medical record; HIHP: Hospital Italiano Health Plan. 
4. Huang JS, Donohue M, Golnari G, Fernandez S, et al. Pediatricians' weight assessment and obesity management practices. BMC Pediatr. 2009; 9:19.

5. Barlow SE, Dietz WH, Klish WJ, Trowbridge FL. Medical evaluation of overweight children and adolescents: reports from pediatricians, pediatric nurse practitioners, and registered dieticians. Pediatrics. 2002; 110(1 Pt 2):222-8.

6. Benson L, Baer HJ, Kaelber DC. Trends in the diagnosis of overweight and obesity in children and adolescents: 19992007. Pediatrics. 2009; 23(1):e153-8.

7. Patel AI, Madsen KA, Maselli JH, Cabana M, et al. Under diagnosis of pediatric obesity during outpatient preventive care visits. Acad Pediatr. 2010; 10(6):405-9.

8. Dilley JK, Martin LA, Sullivan C, Seshadri R, et al. Identification of overweight status is associated with higher rates of screening for comorbidities of overweight in pediatric primary care practice. Pediatrics. 2007; 119(1):e148-55.

9. Benson LJ, Baer HJ, Kaelber DC. Screening for obesityrelated complications among obese children and adolescents: 1999-2008. Obesity. 2011; (19):1077-82.

10. Smith AJ, Skow Á, Bodurtha J, Kinra S. Health information technology in screening and treatment of child obesity: a systematic review. Pediatrics. 2013; 131(3):e894-902.
11. World Health Organization Multicentre Growth Reference Study Group. WHO Child Growth Standards: Length/ height-for-age, weight-for-age, weight-for-length, weightfor-height and body mass index-for-age: Methods and development. Geneva, 2006. [Accessed on: November 14 $4^{\text {th }}$, 2018]. Available at: https://www.who.int/childgrowth/ standards/Technical_report.pdf.

12. Walker $\mathrm{O}$, Strong $\overline{\mathrm{M}}$, Atchinson $\mathrm{R}$, Saunders J, et al. A qualitative study of primary care clinicians' views of treating childhood obesity. BMC Fam Pract. 2007; 8:50 AM.

13. Otero P, Duran P, Setton D, Eymann F, et al. Mismatch between the prevalence of overweight and obese children and adolescents and recording in electronichealth records: a cross-sectional study. Inform Prim Care. 2011;19(2):75-82.

14. Cook S, Weitzman M, Auinger P, Barlow SE. Screening and counseling associated with obesity diagnosis in a national survey of ambulatory pediatric visits. Pediatrics. 2005; 116(1):112-6.

15. Keehbauch J, Miguel GS, Drapiza L, Pepe J, et al. Increased documentation and management of pediatric obesity following implementation of an EMR upgrade and education. Clin Pediatr (Phila). 2012; 51(1):31-8.

\title{
Acute kidney injury and diabetic ketoacidosis in pediatric patients: Risk factors
}

\author{
Carlos Sánchez García, M.D. ${ }^{a}$, Mónica Briones Castellanos, M.D. ${ }^{a}$ and Artemio Velasco Morales, M.D. ${ }^{a}$
}

\begin{abstract}
Acute kidney injury is a cause of morbidity in children with diabetes in developing countries, especially in patients with diabetic ketoacidosis. The objective of this study was to identify the risk factors for acute kidney injury in patients with diabetic ketoacidosis. This was a retrospective cohort study. A total of 50 patients with diabetic ketoacidosis were included; $54 \%$ developed kidney injury. These had higher glucose and uric acid levels (541 mg/dL vs. $407 \mathrm{mg} / \mathrm{dL}, p=0.014$ and $8.13 \mathrm{mg} /$ $\mathrm{dL}$ vs. $5.72 \mathrm{mg} / \mathrm{dL}, p=0.015$, respectively). Uric acid levels above $6.5 \mathrm{mg} / \mathrm{dL}$ showed an odds ratio of $6.910(p=0.027)$ for kidney injury. To conclude, hyperuricemia was a risk factor for acute kidney injury in these patients. Prospective studies are required to determine the role of uric acid in the pathogenesis of acute kidney injury in patients with diabetes.

Key words: diabetic ketoacidosis, acute kidney injury, pediatrics, uric acid.
\end{abstract}

a. Hospital Niño de Saltillo. Saltillo, Coahuila, Mexico.

E-mail address:

Carlos Sánchez, M.D.: sanchez.carlos8516@gmail.com

Funding: None.

Conflict of interest: None.

Received: 3-26-2019

Accepted: 9-16-2019 http: / / dx.doi.org/10.5546/ aap.2020.eng.135

To cite: Sánchez García C, Briones Castellanos M, Velasco Morales A. Acute kidney injury and diabetic ketoacidosis in pediatric patients: Risk factors. Arch Argent Pediatr 2020;118(2):135-138.

\section{INTRODUCTION}

Acute kidney injury is defined as an abrupt decrease in kidney function, leading to electrolyte, acid-base, and water imbalances and waste product accumulation. ${ }^{1}$ The incidence of acute kidney injury has increased, especially in critically-ill hospitalized patients. ${ }^{2}$

The presence of diabetes mellitus is a risk factor for acute kidney injury because it increases renal vulnerability to ischemia. ${ }^{3}$ Acute kidney injury is a predictor of morbidity in patients with type 1 diabetes mellitus; even mild episodes are associated with a cumulative risk for chronic kidney disease. ${ }^{4}$

Diabetic ketoacidosis is a common presentation in patients diagnosed with type 1 diabetes mellitus. ${ }^{5}$ It is also the main cause of 